\title{
Legionella spp. in acute exacerbations of chronic obstructive pulmonary disease: what is the evidence?
}

\author{
S. Ewig
}

Acute exacerbations are a frequent complication during the clinical course of chronic obstructive pulmonary disease (COPD). A recent monograph dealing with COPD exacerbations demonstrated that virtually all issues related to the management of acute exacerbations remain unsettled and controversial, including the definition, aetiology, microbial patterns, and antimicrobial treatment of this condition [1]. This is of particular concern in view of the high burden of this complication on public health resources.

With regards to microbial patterns and their possible involvement in the aetiology of acute exacerbations, it is a common view that Haemophilus influenzae, Streptococcus pneumoniae, and Moraxella catarrhalis are the leading pathogens. Viruses have also been shown to cause acute exacerbations, frequently working as copathogens together with bacterial pathogens [2-4]. Only recently, important extensions of this concept have been provided. Firstly, evidence has grown that microbial patterns may move towards an increasing incidence of Gram-negative enterobacteriaceae and Pseudomonas aeruginosa in more advanced stages of COPD [5]. Similar observations were made in severe exacerbations requiring ventilatory support $[6,7]$. Secondly, several studies found evidence of Chlamydia pneumoniae playing a role as a pathogen or copathogen in acute exacerbations [7-10]. Finally, new challenges emerge from drug-resistant micro-organisms [11]. Overall, bacterial pathogens were found to be present in approximately $50 \%$, and atypical bacterial and viral pathogens in an additional $25 \%$ of cases. The presumptive aetiology in the remaining $25 \%$ of cases remained unclear [12].

In this issue of the European Respiratory Journal, LIEBERMAN et al. [13] present data on a large population, hospitalized with acute exacerbations of COPD, which provides evidence for the first time for Legionella spp. infection as a potential underlying pathogen in as many as $16.7 \%$ of cases [13]. These pathogens were detected serologically by an indirect immunofluorescence method using an in-house kit and applying strict criteria of seroconversion in paired samples. What is the meaning of these findings: should Legionella spp. be included in the list of potential

Dept of Internal Medicine, University of Bonn, Bonn, Germany.

Correspondence: S. Ewig, Medizinischen Universitäts-Poliklinik Bonn, Wilhelmstraße 35, 53111 Bonn. Fax: 492282872112. E-mail: santiago.ewig@ukb.uni-bonn.de pathogens of acute exacerbations of COPD and should antimicrobial treatment regimens, targeted against these pathogens be designed?

Up to now, Legionella spp. have not been reported to form part of the microbial patterns of acute exacerbations. This may simply reflect the principal methodological problems of diagnosing such infections. Legionella spp. can only rarely be cultured from sputum, and bronchoalveolar lavage fluid is usually not suitable in COPD patients with acute exacerbations. In fact, performing bronchoalveolar may prove harmful in these patients. Antigen detection, although highly specific and sensitive, exclusively covers infections by Legionella pneumophila serogroup 1. A paired serum for serology is only rarely obtained, mainly because hospitalization is not usually required for $>2$ weeks. Moreover, usual serology only covers Legionella pneumophila serogroup 1. Using this approach, LIEBERMANN et al. [13] would only have detected Legionella infections in $4 \%$ of cases. Thus, the study confirmed that a vigorous search usually results in unexpected findings. In fact, they provided much indirect evidence that these findings are truely valid.

Legionellosis is known to cause not only pneumonia but also an acute illness, that of Pontiac fever. Fever and chills associated with myalgia, malaise, and headache are the leading symptoms. The symptoms develop progressively. A dry cough may occur as well as minor respiratory symptoms such as sore throat, coryza, and sore eyes. In addition, neurological symptoms have been reported [14]. These clinical features of Pontiac fever are compatible with those described in the report here. No patient had an abrupt onset of exacerbation, and all systemic symptoms were more prevalent in patients with evidence of Legionella infections, however due to the limited number of patients studied the difference was only significant for myalgia/arthralgia. Thus, there is considerable evidence that the group seroconverted for Legionella spp. truely forms a clinically distinguishable group of its own.

Conversely, serology as an indirect diagnostic tool does not provide irrefutable evidence for the involvement of a microbial pathogen. This is particularly true for an in-house kit which is not externally validated. Nevertheless, there are several hints which point at the validity of the serological kits as explained by Lieberman et al. [13] in the discussion. One of the most important is the low rate of false-positive results 
in the control group. The rate of 3\% compares favourably to serological studies of Chlaymdia pneumoniae in COPD and asthma $[15,16]$.

The rate of $16.7 \%$ of infections with Legionella spp. seems to be excessive. In fact, LIEBERMAN et al. [13] cannot exclude the presence of possible epidemic outbreaks during the study period. However, the diversity of Legionella spp. identified argues against the presence of such a confounder. Again, the documented figure is comparable to those figures reported for Chlamydia pneumoniae [7-10].

Overall $65 \%$ of patients with seroconversion for Legionella spp. had evidence for an additional pathogen, including seroconversion for viruses, bacterial isolates in culture, and, Mycoplasma pneumoniae. Dual infections of viruses and bacteria in acute exacerbations have been repeatedly documented, although the subject of the interrelationship of viral and bacterial pathogens has not been clarified satisfactorily [17-19]. "Atypical" pathogens may act as independent pathogens but may also simply favour bacterial superinfection and overgrowth. In any case, the demonstration of multiple pathogens must not be interpreted against a causal role of any "atypical" pathogen, including Legionella spp.

In general, there was some evidence for Legionella infections causing a more severe exacerbation than the other pathogens. Whereas the severity of COPD as assessed by forced expiratory volume in one second, the type of exacerbations according to ANTHONISEN et al. [20], and the rate of patients requiring admission into intensive care were similar, oxygenation was worse in the Legionella group and there was a trend for a higher rate of patients requiring ventilatory support $(15 \%$ versus $9 \%)$ and a higher mortality $(5 \%$ versus $2 \%$ ). These preliminary observations would fit with the experience that Legionella infections tend to cause more severe illness than the majority of other respiratory pathogens [21].

The need for designing an antimicrobial regimen which covers Legionella spp. would impose a significant challenge to clinicans. Macrolides and probably also the new ketolides are not an ideal choice because of the limited activity against Haemophilus influenzae. In the era of a worldwide spread of microbial resistance, the use of fluoroquinolones should be confined to patients with defined risk factors [22]. At present, however, there is no such need. Firstly, the effect of antimicrobial treatment in acute exacerbations is probably confined to the subgroup of patients with ANTHONISEN et al. [20] type-1 exacerbations and those with defined risk factors according to BALL et al. [23] and other studies (cardiopulmonary comorbidity and frequent hospitalizations) [12, 20, 24, $25]$. Even then, the cure rate using placebo is high. Secondly, the study was not designed to examine the effect of antimicrobial treatment directed against Legionella spp., and certainly does not even allow for preliminary conclusions. Thus, only controlled studies can provide a valid estimate about antimicrobial treatment effects in patients with acute exacerbations and evidence of Legionella infections.

To conclude, the present study provides considerable evidence for Legionella spp. as pathogens involved in the aetiology of acute exacerbations of chronic obstructive pulmonary disease. However, the study awaits confirmation from future studies. The true impact of these pathogens in terms of incidence and outcome still remains uncertain. It must be assessed with priority, including diverse populations at risk. In the meantime, unless there is evidence of a local epidemic outbreak of Legionellosis, there is no reason to include Legionella spp. as an additional target in any empirical antimicrobial strategy.

\section{References}

1. Anonymous. Mechanisms and management of COPD exacerbations. Allegra L, Blasi F, eds. Springer Verlag, Milano, 2000.

2. American Thoracic Society. Standards for the diagnosis and care of patients with chronic obstructive pulmonary disease. Am J Respir Crit Care Med 1995; 152: S78-S83.

3. Siafakas NM, Vermeire P, Pride NB, et al. ERS consensus statement: optimal assessment and management of chronic obstructive pulmonary disease (COPD). Eur Respir J 1995; 9: 1398-1420.

4. Monsó E, Ruiz J, Rosell A, et al. Bacterial infection in chronic obstructive pulmonary disease. A study of stable and exacerbated outpatients using the protected specimen brush. Am J Respir Crit Care Med 1995; 152: 1316-1320.

5. Eller J, Ede A, Schaberg T, Niederman MS, Mauch H, Lode $\mathrm{H}$. Infective exacerbations of chronic obstructive pulmonary disease. Relation between bacteriologic etiology and lung function. Chest 1998; 113: 15421548.

6. Fagon JY, Chastre J, Trouillet JL, et al. Characterisation of distal microflora during acute exacerbations of chronic bronchitis. Am Rev Respir Dis 1990; 142: 1004-1008.

7. Soler N, Torres A, Ewig S, et al. Bronchial microbial patterns in severe exacerbations of chronic obstructive pulmonary disease (COPD) requiring mechanical ventilation. Am J Respir Crit Care Med 1998; 157: 1498-1505.

8. Beaty CD, Grayston JT, Wang SP, Kuo CC, Reto CS, Martin TR. Chlamydia pneumoniae, strain TWAR, infection in patients with chronic obstructive pulmonary disease. Am Rev Respir Dis 1991; 144: 1408-1410.

9. Blasi F, Legnani D, Lombardo WM, et al. Chlamydia penumoniae infection in acute exacerbations of chronic obstructive pulmonary disease (COPD). Eur Respir J 1993; 6: 19-22.

10. Mogulkoc N, Karakurt S, Isalska B, et al. Acute purulent exacerbation of chronic obstructive pulmonary disease and Chlamydia pneumoniae infection. Am J Respir Crit Care Med 1999; 160: 349-353.

11. Anzueto A, Niederman MS, Tillotson GS. Etiology, susceptibility, and treatment of acute bacterial exacerbations of complicated chronic bronchitis in the primary care setting: ciprofloxacin $750 \mathrm{mg}$ b.i.d. versus clarithromycin $500 \mathrm{mg}$ b.i.d. Bronchitis study group. Clin Ther 1998; 20: 885-900.

12. Ewig S, Soler N, Torres A. Chronic obstructive pulmonary disease and infection: from stable patients to pneumonia. Clin Pulm Med 1999; 6: 1-8.

13. Lieberman D, Lieberman D, Shmarkov $\mathrm{O}$, et al. 
Serological evidence of Legionella species infection in acute exacerbation of COPD. Eur Respir J 2002; 19: 392-397.

14. Glick TH, Gregg MB, Berman B, Mallison G, Rhodes WW Jr, Kassanoff I. Pontiac fever. An epidemic of unknown etiology in a health department: I. Clinical and epidemiologic aspects. Am J Epidemiol 1978; 107: 149-160.

15. Miyashita N, Niki $Y$, Nakajima M, Kawane $H$, Matsushima T. Chlamydia pneumoniae infection in patients with diffuse panbronchiolitis and COPD. Chest 1998; 114: 969-971.

16. Gencay M, Rudiger JJ, Tamm M, Soler M, Perruchoud AP, Roth M. Increased frequency of Chlamydia pneumoniae antibodies in patients with asthma. $\mathrm{Am}$ J Respir Crit Care Med 2001; 163: 1097-1100.

17. McNamara MJ, Philipas IA, Williams OB. Viral and mycoplasma pneumoniae infections in exacerbations of chronic lung disease. Am Rev Respir Dis 1969; 100: 19-24.

18. Buscho LO, Saxtan D, Shultz PS, Finch E, Muffson MA. Infection with viruses and Mycoplasma pneumoniae during exacerbations of chronic bronchitis. J Infect Dis 1978; 137: 377-383.

19. Smith CB, Golden CA, Kanner RE, Renzetti AD. Association of viral and mycoplasmal infections with respiratory illness in patients with chronic obstructive pulmonary diseases. Am Rev Respir Dis 1980; 121: 225-232.

20. Anthonisen N, Manfreda J, Warren CPW, Hershfield ES, Harding GKM, Nelson NA. Antibiotic therapy in excerbations of chronic obstructive pulmonary disease. Ann Intern Med 1987; 106: 196-204.

21. Ewig S. Community-acquired pneumonia. Epidemiology, risk, and prognosis. Eur Respir Mon 1997; 3: 1335 .

22. Heffelfinger JD, Dowell SF, Jorgensen JH, et al. Management of community-acquired pneumonia in the era of pneumococcal resistance: a report from the Drug-Resistant Streptococcus pneumoniae Therapeutic Working Group. Arch Intern Med 2000; 160: 1399-1408.

23. Ball P, Harris JM, Lowson D, Tillotson G, Wilson R. Acute infective exacerbations of chronic bronchitis. QJM 1995; 88: 61-68.

24. Sachs APE, Koeter GH, Groenier KH, van der Waaiji $\mathrm{D}$, Schiphuis J, Meyboom-de Jong B. Changes in symptoms, peak expiratory flow, and sputum flora during treatment with antibiotics of exacerbations in patients with chronic obstructive pulmonary disease in general practice. Thorax 1995; 50: 758-763.

25. Saint S, Bent S, Vittinghof E, Grady D. Antibiotics in chronic obstructive pulmonary disease exacerbations. JAMA 1995; 273: 957-960. 